\title{
Perforation of the jejunum secondary to AIDS-related gastrointestinal Kaposi's sarcoma
}

\author{
ERIC M YOSHIDA MD FRCPC, NORMAN HL CHAN MD FRCPC, CLIFFORD CHAN-YAN MD FRCPC, ROBERT M BAIRD MD FRCSC
}

EM Yoshida, NHL Chan, C CHAN-Yan, RM BAIRD. Perforation of the jejunum secondary to AIDS-related gastrointestinal Kaposi’s sarcoma. Can J Gastroenterol 1997;11(1):38-40. Intestinal perforation in human immunodeficiency virus-positive patients due solely to Kaposi's sarcoma (KS) has rarely been described. A homosexual man with acquired immunodeficiency syndrome-related KS who presented with an acute abdomen is presented. He was found to have a jejunal perforation through a small KS lesion. There were no infectious organisms identified at the site of perforation.

Key Words: Acquired immune deficiency syndrome, Human immunodeficiency virus, Intestinal perforation, Kaposi's sarcoma

\section{Perforation du jéjunum secondaire à un sarcome} de Kaposi gastro-intestinal associé au SIDA

RÉSUMÉ : On a rarement décrit la perforation intestinale uniquement due au sarcome de Kaposi chez les patients infectés par le virus de l'immunodéficience humaine acquise. On présente ici le cas d'un patient homosexuel atteint d'un sarcome de Kaposi associé au syndrome de l'immunodéficience humaine acquise ayant consulté pour un abdomen aigu. Il s'est révélé atteint d'une perforation du jéjunum attribuable à une petite lésion du sarcome de Kaposi. Aucun organisme infectieux n'a été identifié au siège de la perforation.
$\mathrm{K}^{\mathrm{s}}$ aposi's sarcoma $(\mathrm{KS})$ is a multicentric malignant vascular neoplasm of unknown cause. The classic form of this disease is an indolent cutaneous neoplasm that afflicts mainly elderly Mediterranean and Jewish men. The endemic form of this disease manifests as a locally aggressive neoplasm found in Africans (1). This disease is now well known to clinicians as a common manifestation of the acquired immunodeficiency syndrome (AIDS). As a manifestation of AIDS, KS may be limited to the skin or may present as aggressive disseminated disease with visceral involvement. Involvement of the gastrointestinal tract by $\mathrm{KS}$ occurs in up to $40 \%$ of patients with AIDS (2). Gastrointestinal KS is rarely symptomatic, but can occasionally present as gastrointesti- nal bleed (3). Reported instances of intestinal perforation due to KS have been rare. We report a human immunodeficiency virus (HIV)-positive man with cutaneous $\mathrm{KS}$ who had a perforation of the jejunum due to KS. The current literature pertaining to this subject is reviewed.

\section{CASE PRESENTATION}

A 36-year-old HIV seropositive homosexual man, with a three-year history of cutaneous $\mathrm{KS}$ and primary pulmonary hypertension, presented with recent onset of cramp-like mid-abdominal pain and frequent loose stools. He did not have fever, chills, nausea or vomiting.

Background history revealed that his CD4 count two

Department of Laboratory Medicine and Pathology, St Paul's Hospital, Vancouver, British Columbia

Correspondence: Dr NH Chan, Department of Laboratory Medicine and Pathology, St Paul's Hospital, 1081 Burrard Street, Vancouver, British Columbia V6Z 1Y6. Telephone 604-682-2344, fax 604-631-5208, e-mail nchan@medlab.stpaulshosp.bc.ca

Received for publication September 6, 1994. Accepted February 5, 1996 


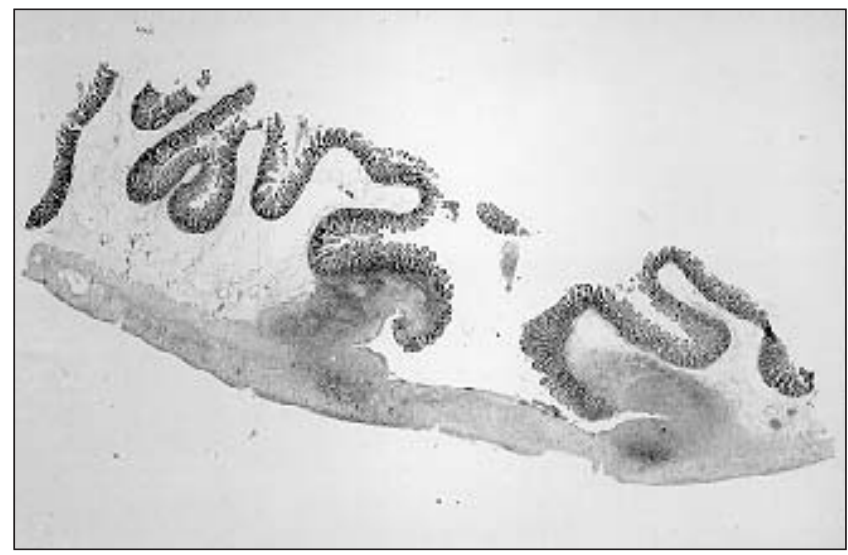

Figure 1) Photomicrograph showing an ulcer of the small bowel infiltrated with Kaposi's sarcoma. There is attenuation of the bowel wall in the centre of the ulcer $(x 2.8)$

months previously was $140 / \mathrm{mm}^{3}$. Cutaneous KS was the only AIDS defining illness. There was no history of opportunistic infections. His pulmonary hypertension had been investigated three years previously and was felt to be primarily AIDS-related. Medications at admission included zidovudine, didanosine, cotrimoxazole, erythromycin, digoxin and diltiazem. There was no history of nonsteroidal antiinflammatory drug use.

Physical examination revealed an acutely distressed patient. Auscultation of the chest was unremarkable. Examination of the cardiovascular system revealed jugulovenous distension $10 \mathrm{~cm}$ above the sternal angle, a right parasternal heave, displaced apical impulse, a right-sided third heart sound and a II/VI pansystolic murmur at the left sternal border. Examination of the abdomen revealed diffuse tenderness and decreased bowel sounds. Dermatological survey revealed lesions consistent with KS on the forehead and upper body.

Initial laboratory data revealed the following: leukocyte count, $4.5 \times 10^{-9} / \mathrm{L}$; hemoglobin, $131 \mathrm{~g} / \mathrm{L}$; platelet count, $171 \times 10^{-9} / \mathrm{L}$; normal serum electrolytes; serum creatinine, $90 \mathrm{~mol} / \mathrm{L}$ (normal 40 to 120); aspartate aminotransferase, $52 \mathrm{U} / \mathrm{L}$ (normal greater than 40); alkaline phosphatase, $321 \mathrm{U} / \mathrm{L}$ (normal 35 to 105); and serum lactate, $6 \mathrm{mmol} / \mathrm{L}$ (normal 0.5 to 1.8). Abdominal radiographs revealed the presence of free air.

Intraoperatively, five slightly raised pigmented lesions consistent with $\mathrm{KS}$ were seen in the jejunum and ileum. One of the lesions in the jejunum was noted to have a perforation. Resection of the affected bowel was undertaken followed by primary reanastomosis.

Gross pathological examination of the jejunum revealed a $1 \mathrm{~mm}$ perforation in an ulcerating KS lesion.

Histopatholological examination of the solid area surrounding the perforation revealed a malignant spindle cell neoplasm with numerous vascular clefts, features typical of KS (Figures 1,2). Special stains, including a rhodamineauromine fluorescent stain for mycobacteria, periodic acidSchiff stain for fungus, methenamine silver stain for Pneumo-

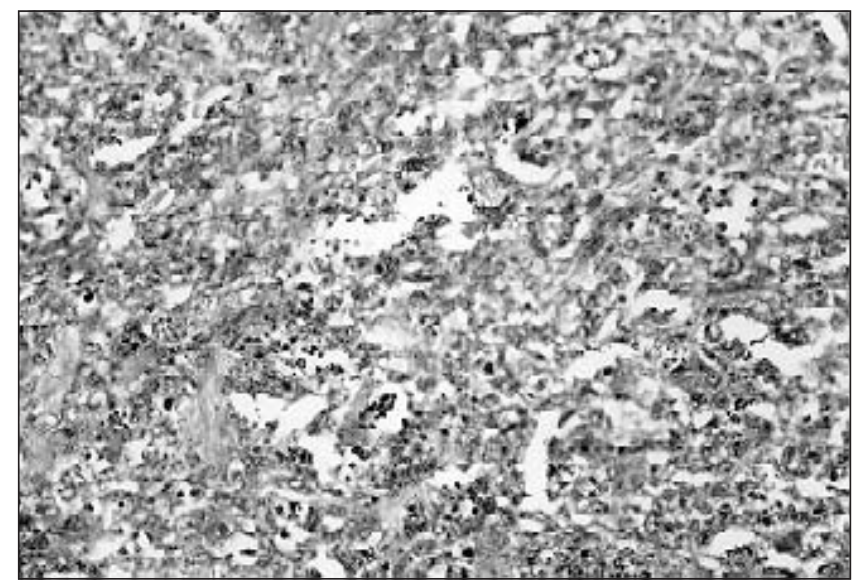

Figure 2) Higher magnification of the ulcer in Figure 1 revealing spindle and vascular proliferation typical of Kaposi's sarcoma (x268)

cystis carinii and in situ hybridization for cytomegalovirus (CMV), were all negative. The final pathological diagnosis was perforation of the jejunum secondary to KS. The patient died of respiratory complications in the intensive care unit following surgery.

\section{DISCUSSION}

AIDS-related KS can involve every aspect of the gastrointestinal tract from the oropharynx to the rectum. Hepatobiliary, pancreatic and splenic involvement have also been described (3). KS of the gut is typically asymptomatic. Endoscopically, gastrointestinal KS appears as purple nodules, polypoid masses or hemorrhagic macules. These lesions are frequently submucosal and may be entirely missed on endoscopic biopsy (2). Other manifestations of gastrointestinal KS include diarrhea and intussusception (4), appendicitis (5) and obstruction due to bulky disease (3), as well as symptoms referable to nonintestinal intra-abdominal involvement, such as cholangitis secondary to biliary involvement (6).

Whereas intestinal perforation is a well described complication of gastrointestinal CMV infection $(7,8)$, intestinal perforation due to KS alone has rarely been reported. The first case was reported by Mitchell and Feder (9) in 1949. They described an elderly Jewish man who had obstructive symptoms and developed an acute abdomen while straining at stool. Postmortem examination revealed bulky KS encircling the jejunum with perforation. In the AIDS era there have been several reports of intestinal perforation associated with gastrointestinal KS. Cases of KS presenting with duodenal perforation (10) and ruptured appendicitis (5) have also been reported. However, the etiology of the perforation in most of these cases is not attributed to KS alone. Perforation of the terminal ileum with KS in close proximity to the perforation and with coexisting CMV vasculitis was reported by Burke et al (11). Ileal perforation with mycobacteria and candida within a KS mucosal ulceration was also reported by Bieluch and colleagues (12). These authors believed that superinfection of the KS lesion was a contributing factor leading to perforation. Intestinal mycobacterial infection has 
been reported to result in bowel perforation (13). Intestinal lymphoma is yet another important cause of AIDS-related small bowel perforation $(8,14)$.

Our patient with AIDS-related KS had a jejunal perforation secondary to KS but did not have bulky disease, making this case significantly different from the patient reported by Mitchell and Feder (9). In our patient this perforation was a direct result of central ulceration within a small KS lesion. There were no other identifiable causes, either infectious or neoplastic, to cause this small bowel perforation.

Another interesting AIDS-related illness in our patient was primary pulmonary hypertension. Pulmonary hypertension has been recognized to be associated with HIV, al-

\section{REFERENCES}

1. Karp JE, Groopman JE, Broder S. Cancer in AIDS. In: DeVita VT, Heilman S, Rosenberg SA, eds. Cancer, Principles \& Practice of Oncology. Philadelphia: JB Lippincott Company, 1993:2093-110.

2. Friedman SL, Wright TL, Altman DF. Gastrointestinal Kaposi's sarcoma in patients with acquired immunodeficiency syndrome. Gastroenterology 1985;89:102-8.

3. Friedman SL. Kaposi's sarcoma and lymphoma of the gut in AIDS. Baillieres Clin Gastroenterol 1990;4:455-75.

4. Kadakia SC, Kadakia S, Westphal W. Gastrointestinal Kaposi's sarcoma as the first manifestation of acquired immunodeficiency syndrome. South Med J 1992;85:37-9.

5. Ravalli S, Vincent RA, Beaton H. Primary Kaposi's sarcoma of the gastrointestinal tract presenting as acute appendicitis. Am J Gastroenterol 1990;85:772-3. (Lett)

6. Robinson G, Wilson SE, Williams RA. Surgery in patients with acquired immunodeficiency syndrome. Arch Surg 1987;122:170-5.

7. Kram HB, Shoemaker WC. Intestinal perforation due to cytomegalovirus infection in patients with AIDS. Dis Colon Rectum 1990;33:1037-40.

8. Davidson T, Allen-Mersh TG, Miles AJG, et al. Emergency laparotomy in patients with AIDS. Br J Surg 1991;78:924-6. though its occurrence is rare (15). Its association with our patient's intestinal perforation was coincidental, but was a major factor in his death.

\section{CONCLUSIONS}

This case demonstrates that intestinal perforation can be secondary to KS. Unlike the original case reported over 40 years ago in the pre-AIDS era, gastrointestinal KS does not have to manifest as bulky disease with resulting obstruction in order to cause perforation. KS itself should be considered in the differential diagnosis of any HIV seropositive patient presenting with a bowel perforation. This may have therapeutic and clinical relevance.

9. Mitchell N, Feder I. Kaposi's sarcoma with secondary involvement of the jejunum, perforation and peritonitis. Ann Intern Med 1949;31:324-9.

10. Carratala J, Lacasa JM, Mascaro J, Torras JT. AIDS presenting as duodenal perforation due to Kaposi's sarcoma. AIDS 1992;6:241-2. (Lett)

11. Burke G, Nichols L, Balogh K, et al. Perforation of the terminal ileum with cytomegalovirus vasculitis and Kaposi's sarcoma in a patient with acquired immunodeficiency syndrome. Surgery 1987;102:540-5.

12. Bieluch VM, Wagner S, Kim K, Freimer EH. Unusual manifestations of gastrointestinal Kaposi's sarcoma in acquired immunodeficiency syndrome. Arch Dermatol 1988;124:652-4. (Lett)

13. Senise JF, Hamrick PA, Guidugli RB, Ribera JM, Siquera SA. [Ileal loop perforation caused by tuberculosis in patients with acquired immunodeficiency syndrome]. Rev Paul Med 1991;109:61-4.

14. Sheridan R, Garland D, Pilar J, Pollard W. AIDS-related small bowel lymphoma presenting with perforation. Mil Med 1989;154:381-2. (Lett)

15. Mette SA, Pavelsky HI, Pietra GG, et al. Primary pulmonary hypertension in association with human immunodeficiency virus infection. Am Rev Respir Dis 1992;145:1196-200. 


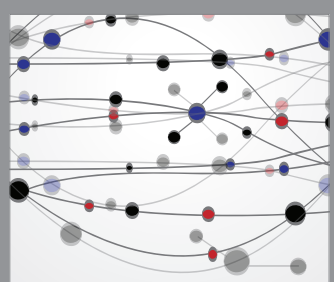

The Scientific World Journal
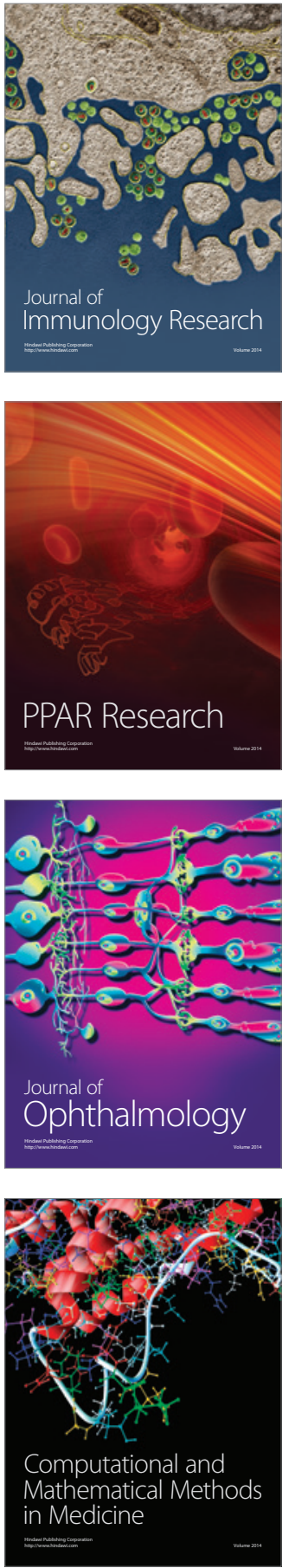

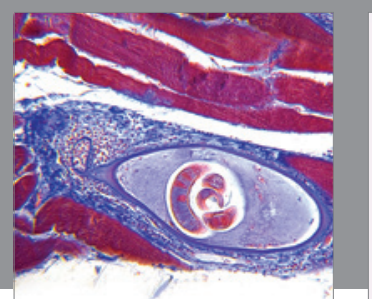

Gastroenterology Research and Practice

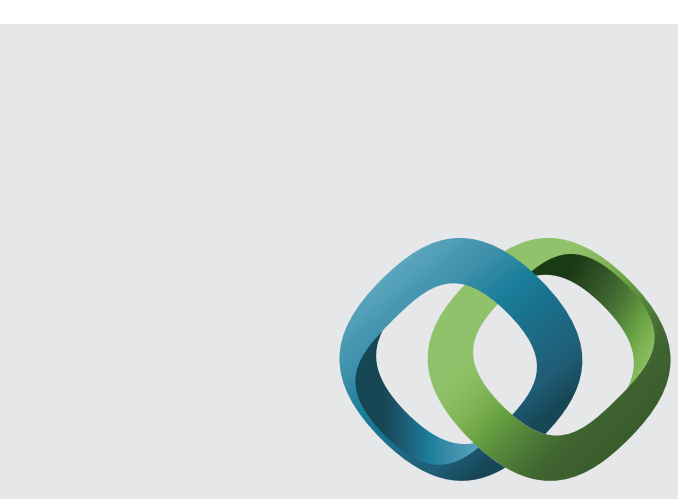

\section{Hindawi}

Submit your manuscripts at

http://www.hindawi.com
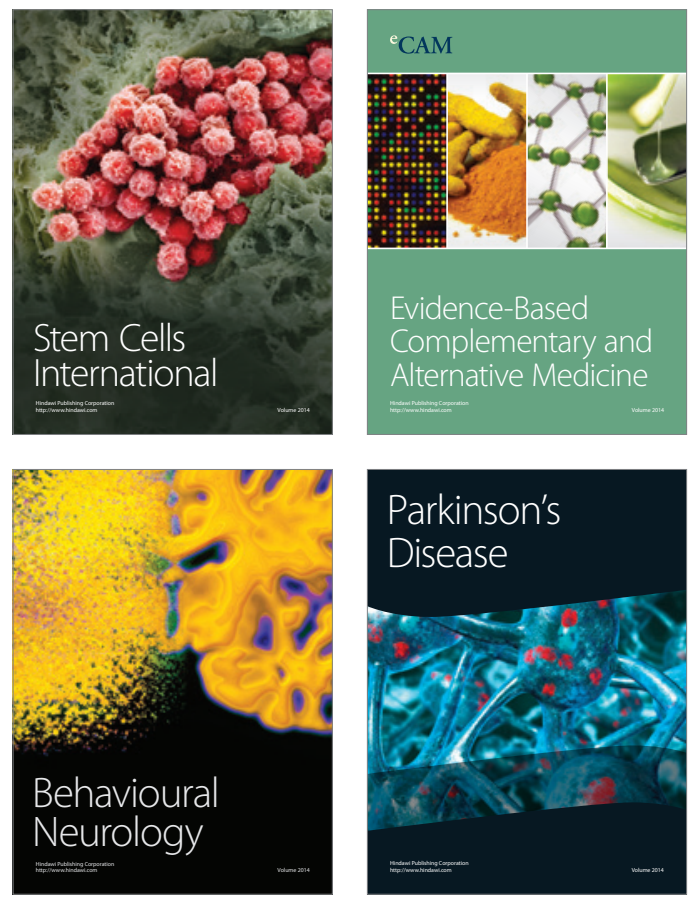
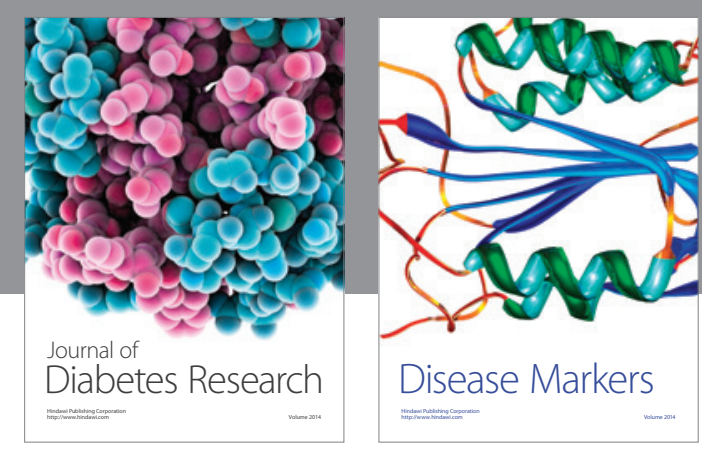

Disease Markers
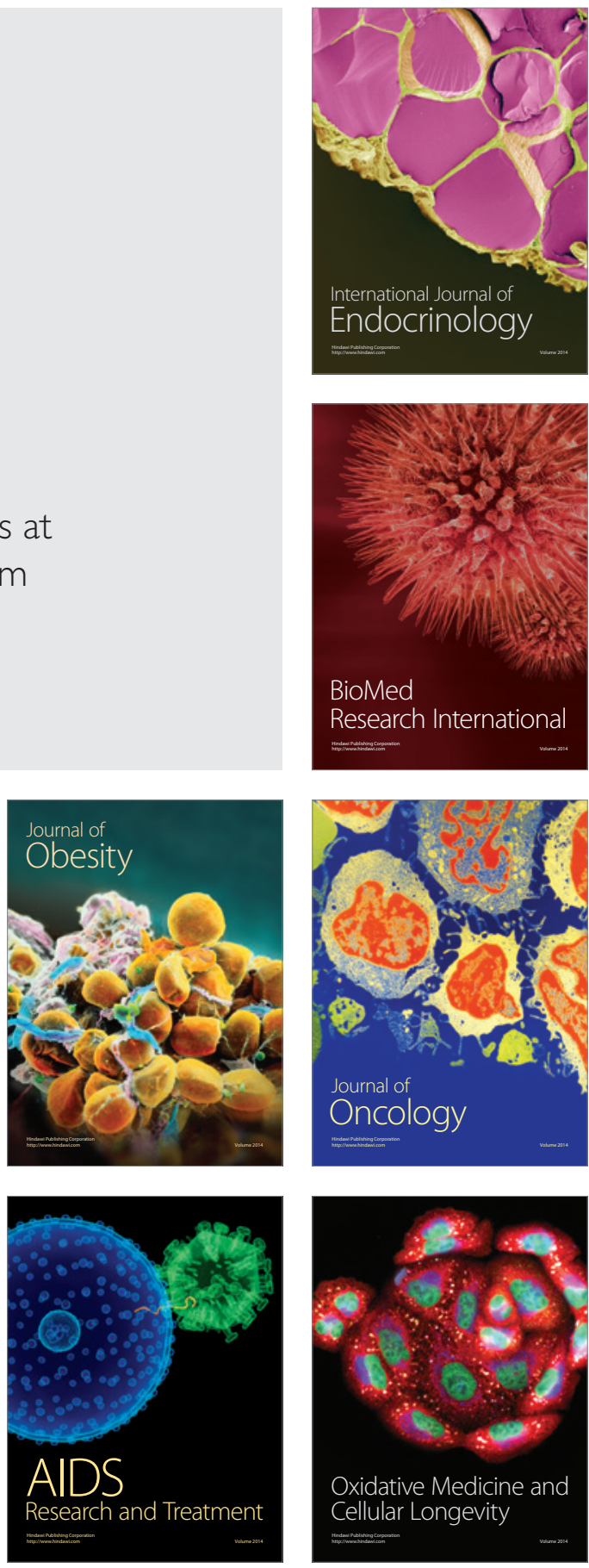